\title{
Protection of biodiesel and oil from degradation by natural antioxidants of Egyptian Jatropha
}

\author{
G. El Diwani; *S. El Rafie; S. Hawash
}

National Research Center, Department of Chemical Engineering, Egypt

Received 24 February 2009; $\quad$ revised 25 April 2009; accepted 12 May 2009; available online 1 June 2009

\begin{abstract}
Residue of methanolic extract of Egyptian Jatropha curcas contains bioactive substances such as phenolic compounds, which succeeded to be used as natural antioxidants for the protection of oils and their corresponding biodiesel against oxidative deterioration. In the present work, the residue of Jatropha roots were extracted with methanol and resulting residues, were investigated regarding their content of total phenolic compounds by folin-Cioalteau assay. Further, the antioxidant activities of the extracts were characterized by the 2,2-diphenyl-1-picrylhydrazyl radical method and proved remarkable results. Oxidation stability of Jatropha oil, used fried oil and olive oil and their corresponding biodiesel obtained by conventional transesterification were tested using thermal oxidation. Natural antioxidants such as ( $\alpha$-trocopherol), synthetic antioxidants as butylated hydroxytoluene and natural Jatropha root extract were used in the present study in comparison to investigate their addition effect on the oxidative stability of oils and their corresponding biodiesel. In the rapied thermal treatment test, results showed that addition of butylated hydroxytoluene $0.25 \%$ was able to stabilize Jatropha oil $6 \mathrm{~h}$, but poorly stabiliz biodiesel. Addition of $0.25 \% \alpha$-trocopherol to Jatropha oil showed less oxidation stability after $2 \mathrm{~h}$ thermal treatment. Crude root extract addition at $0.25 \%$ to Jatropha oil showed good stability up to $4 \mathrm{~h}$ thermal treatment while addition of root extract at $0.25 \%$ to biodiesel showed better stability up to $6 \mathrm{~h}$ thermal treatment. Besides addition of $220 \mathrm{ppm}$ crude root extract to biodiesel was enough sufficient to occure oxidative stabilization. Also Jatropha root residue addition at 400 ppm was effective antioxidant for fresh Jatropha oil.
\end{abstract}

Keywords: Phenolic compounds; Thermal stability; Transesterification; Vegetable oil

\section{INTRODUCTION}

Diesel fuels play an important role in the industrial economy of a country. These fuels run a major part of the transport sector and their demand is increasing steadily, requiring an alternative fuel which is technically feasible, economically. Competitive, environmentally acceptable and readily available (Srivastava and Prasad, 2000); Vegetable oils are widely available from various sources and the glycerides present in the oils can be considered as a viable alternative for diesel fuel (Ali et al., 1995; Shay, 1993).

Recently, new methods for determination of oxidative stability of vegetable oils at frying temperatures were proposed (Gertz and Kochhar, 2001). Despite the large number of methods for determination of oxidative stability of edible oils, papers dealing with its determination at frying temperatures (commonly between $140{ }^{\circ} \mathrm{C}$ and $180^{\circ} \mathrm{C}$ ) are scarce. The reactions and mechanisms taking place in the degradation of

*Corresponding Author Email: shelrafie0000@yahoo.com Tel.: +2 333 71433; Fax: +2 35570931 vegetable oils are very dependant on the heating temperature. For instance, for temperatures up to 120 ${ }^{\circ} \mathrm{C}$, the main reactions are hydrolysis and oxidation induced by moisture and atmospheric oxygen, where for temperatures above $120^{\circ} \mathrm{C}$ polymerization reactions also become important (Gertz et al., 2000). Another advantage of the determination of oxidative stability at frying temperatures would be a high analysis through put. As a rate of a reaction increases as the temperature increase, the induction time and, then, the analysis time decrease.

Antioxidant is a chemical that delays the start or slows the rate of lipid oxidation reaction. It inhibits the formation of free radical and hence contributes to the stabilization of the lipid sample (Ling, 2006). Synthetic antioxidants such as butylated hydroxyl toluene (BHT), is effective in the protection of unsaturated fats and oils. However, the use of these synthetic antioxidants is discouraged because of their toxicity and carcinogenicity (Jeong et al., 2004; Shahidi, 1997). 
Natural antioxidants are constituents of many fruits and vegetables and they have attracted a great deal of public and scientific attention because of their anticarcinic potential. Biodiesel is an environment friendly liquid fuel similar to petrodiesel in combustion properties. As biodiesel chemically is an ester molecule there is every possibility that in the presence of air or oxygen it will be hydrolyzed to alcohol and acid. Presence of alcohol will lead to reduction in flash point and presence of acid will increase total acid number. All these make methyl ester relatively unstable on storage and cause damage to engine for biodiesel. Stability of biodiesel is inferior compared to petrodiesel and therefore doping of biodiesel in petrodiesel will affect the stability of fuel significantly (Dunn and Knoth, 2003). The poor stability of biodiesel is due to the double bond in the fatty acids, which may lead to gum formation. Mc Cormick et al. (2006), have shown that at very high levels of oxidation biodiesel blends can separate into two phases causing fuel pump and injector operational problems. Therefore, it was considered to include a limit for oxidation stability in the existing quality standard for biodiesel. During the oxidation process, the fatty acid methyl ester usually forms a radical next to the double bond. This radical quickly binds with the oxygen in the air, which is a biradical. This forms peroxide radical. The rapid radical destruction cycle begins after that. This peroxide radical immediately creates a new radical from the fatty acid methyl ester, which in turn binds with oxygen in the air. Then the destructive radical auto-oxidation cycle starts. During this process, up to 100 new radicals are created quickly from one single radical, meaning that decomposition occurs at an exponentially rapid rate and results in formation of a series of by-products (Hui, 1996). Recently Mc Cormick et al. (2007) showed that dimerization of the peroxide species is not the only mechanism for molecular weight growth and deposit formation in biodiesel and identified a number of other mechanism by which biodiesel can degrade.

Vegetable oils contain natural antioxidants. The most common are tocopherols, which are hindered phenolic chain breaking antioxidants. Chain breaking antioxidants are highly reactive with free radicals and form stable compounds that do not contribute to the oxidation chain reaction. For example, soya oils were found to contain approximately $500-3000 \mathrm{ppm}$ of tocopherols (Tarandjiska et al., 1996) along with other antioxidants such as sterols and tocopherols and these are not affected by ester preparation process (Van Gerpen et al., 1997). Biodiesel produced by distillation typically contains little or no natural antioxidant and is less stable than biodiesel that contains natural antioxidants. The stability of biodiesel can be improved by adding synthetic antioxidants (Waynick, 2005). The two most common types of antioxidants are phenolictypes and amminic-types. As can be seen in Fig. 1 on mechanism of antioxidant action, the antioxidant contains a highly labile hydrogen that is more easily abstracted by a peroxy radical than fatty oil or ester hydrogen. The resulting antioxidant free radical is either stable or further reacts to form a stable molecule that does not contribute to the chain oxidation process. In this way chain breaking antioxidants interrupt the oxidation chain reaction.

Jatropha curcas is a nut belonging to the Euphobiaceae family. It is cultivated in central and south America, south east Asia, Tndia and Africa (Gubitz et al., 1999). Recently, Jatropha curcas tree has been successfully cultivated in Upper Egypt and its fruit gives non edible oil Hawash et al. (2009). Jatropha
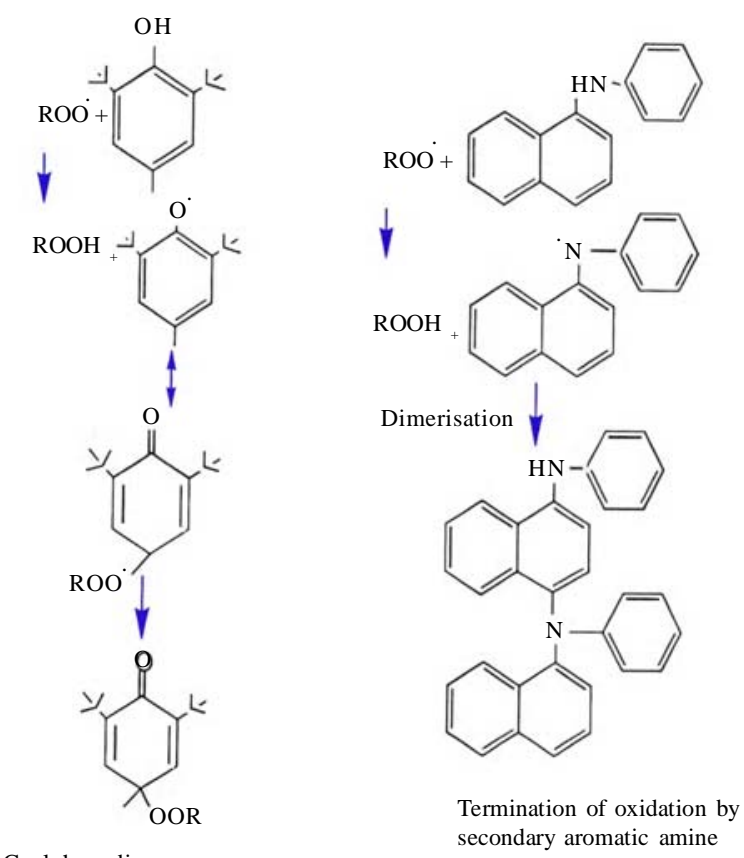

Cyclohexadienone

Terminated of oxidation by sterically hindered phenol

Fig. 1: Mechanism of antioxidants action 
curcas grow well because of its low moisture demands, fertility requirements and tolerance to high temperatures (Kaushik et al., 2007). All parts of Jatropha curcas plant have their own uses. Like many other Jatropha species, Jatropha curcas is a succulent tree that sheds its leaves during the dry season.

It is well adaptor to arid and semi-arid conditions and often used for erosion control. The leaves are used in traditional medicine against coughs or as antiseptics after birth, and the branches are chewing sticks (Gubitz et al., 1999).The latex produced from the branches is useful for wounds healing and others medical uses. Each fruit contains 2-3 oblong black seeds which can produce oil. The seed kernel oil contained 40-60 \% (w/ w) oil (Makkar et al., 1997). The seed oil extracted is found useful in medicinal and veterinary purpose, as insecticide, for soap production and as fuel substitute (Gubitz et al., 1999). The composition of Jatropha curcas oil from Egypt consists of main fatty acid such as Palmitic $18.22 \%$, stearic $5.14 \%$, Oleic $28.46 \%$ and Linoleic 48.18 \% (Hawash et al., 2009). This made oils suitable for biodiesel production. However, the chemical compositions of the oil vary according to the climent and locality (Salimon and Abdullah, 2008).

Although Jatropha seeds is main feed stock available for biodiesesl production, but it has large fraction of unsaturated fatty acids. So this study is concentrated on oxidation stability of Jatropha oil and its corresponding biodiesel. Westbrook (2005) evaluated test methods to measure the oxidative stability of net biodiesel. Sarin et al. (2007) studied two approachs for improving oxidation stability of Jatropha biodiesel. First with doping of Jatropha methyl esters with stabilizer or antioxidants such as (2,6ditertiarybutyl hydroxyl toluene), bis2,6-ditertialybutyl phenol derivative, mixed butylated phenol and aminic antioxidant octylated butylated diphenyl amine. Although, they found possible to meet the desired energy specification using antioxidants, but are costly chemicals. Therefore, another set of study was under taken to extract natural antioxidants from Egyptian Jatropha organs especially roots. It was decided to study the effect of dosage of natural antioxidants addition on oxidation stability of Jatropha oil and biodiesel compared to olive oil and used fried oil and there corresponding biodiesel. Quantified results from DPPH method in BHT equivalent was used to compare the oxidative stability of vegetable oils and biodiesel.
This research has been performed in the National Research Center, Egypt on 2008 - 2009.

\section{MATERIALS AND METHODS}

Vegetable oils including Jatropha curcas, olive oil and used fried oil were purchased locally. Antioxidants $\alpha$-Tocopherol and butylated hydroxyl toluene (BHT) and Diphenyl picryl - hydrazyl (DPPH), isooctane were purchased from Sigma-Aldrich Company. Other chemicals, including potassium hydroxide, acetic acid and methanol were purchased locally. Natural antioxidant methanol are extract from Egyptian Jatropha roots. All other chemicals were pure grade and purchased locally.

Synthetic antioxidants such as butylated hydroxytoluene was tested at levels of $0.25 \%$, may possess somewhat differing solubilities and effectiveness. The effectiveness of an antioxidant can depend on a variety of factors, including the fatty acid profile of the oil or fat, the amount of naturally occurring antioxidants and storge or conditions (Knothe, 2007). Natural antioxidants such as tocopherols and tocotrienols in vegetable oils is affected by the refining process (Wijtmans et al., 2004). Antioxidants such as phenols and amines either have a hydrogen atom, phenols becom quinones or react with a radical in an addition fashion. Oxygen scavengers and ascorbic acid can regenerate spentantioxidant and singlet oxygen quenchers such as $\beta$-carotene can be as oxidation inhibitors.

\section{Biodiesel preparation}

A series of biodiesel samples have been prepared using alkali catalized method. Methanol (1:5 molar oil: alcohol) was mixed with $\mathrm{KOH}$ (1 wt \%) added to the reactor containing oil slowly with stirring. The reaction mixture was refluxed for $2 \mathrm{~h}$. After completion of the reaction, the reaction mixture was transferred to a separating funnel and both the phases were separated. Upper phase was biodiesel and lower part was glycerin. Alcohol from both the phases was distilled off under vacuum. The glycerin phase was neutralized with acid and stored as crude glycerin. Upper phase i.e. methyl ester (biobiesel) was washed with hot water twice to remove traces of glycerin, unreacted catalyst and soap formed during the transesterification. The residual product was kept under vacuum to get rid of residual moisture (Kumara et al., 2004; Sarin et al., 2007). 
Oil and biodiesel samples for thermally induced oxidation at $180^{\circ} \mathrm{C}$ and $60^{\circ} \mathrm{C}$, respectively

Two $g$ of olive oil, used fried oil and Jatropha oil and their corresponding prepared biodiesels were placed singly in a $10 \mathrm{~mL}$ caped test tube. $0.25 \% \alpha$-tocopherol, $0.25 \%$ BHT and $0.25 \%$ Jatropha residue of root extract were added singly and respectively for each test tube and thermally oxidized at $180^{\circ} \mathrm{C}$ for oils and $60^{\circ} \mathrm{C}$ for biodiesel along $8 \mathrm{~h}$, respectively. All samples were prepared in triplicate and analyzed using DPPH method. Antioxidants are generally used at levels of $100-400$ $\mathrm{pm}$. They possess somewhat differing solubilities and effectiveness. Besides, systems with more than one antioxidant, results in primary and secondary antioxidants. DPPH is a stable free radical and accepts an electron or hydrogen radical to become a stable diamagnetic molecule (Lui and Yao, 2007) The reduction capability of DPPH is determined by the decrease in its absorbance at $517 \mathrm{~nm}$ induced by antioxidants. Now, DPPH has been widely using in assessment of radical scavenging activity because of its ease and convenience.

\section{DPPH measurement}

The conventional DPPH method uses methanol as solvent dissolves biodiesel, but does not dissolve oils. Proper organic solvent for both DPPH and oil samples should be selected first. Lee et al. (2007) showed that isooctane could dissolve both DPPH and oil samples. Two milliliters of $0.01 \mathrm{mM}$ DPPH in isooctane were

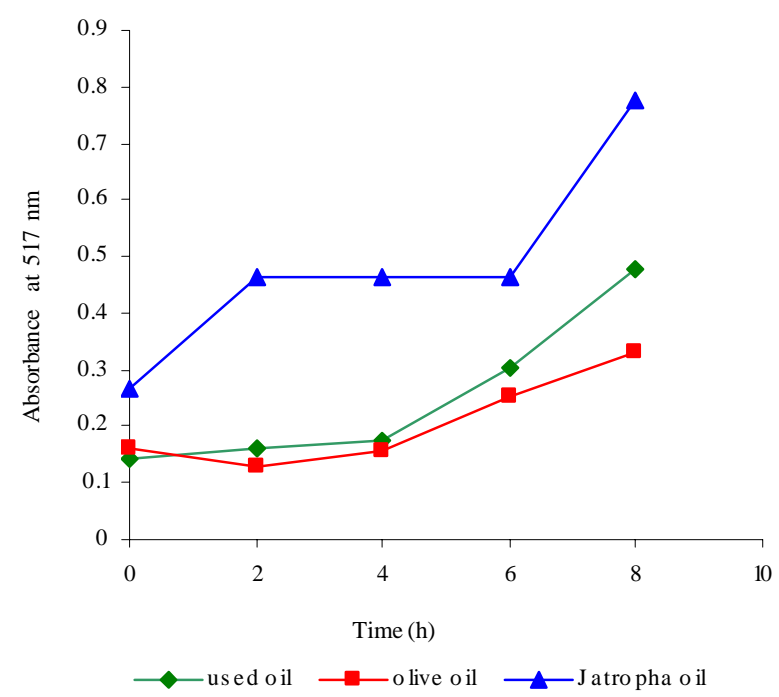

Fig. 2: Thermal degradation of oils at $180^{\circ} \mathrm{C}$ mixed with two g oil sample in caped test tube and after 30 min standing in dark, the absorbance of the sample mixture was measured at $517 \mathrm{~nm}$ using spectrophotometer Model (HACH DR 2000). Free radical scavenging activity from DPPH method was expressed in BHT equivalents and calculated as follows:

$\mathrm{AI} \%=[\mathrm{Ao}-\mathrm{Ac}] / \mathrm{Ao}] * 100$

Where Ao = Initial absorbance (control); $\mathrm{Ac}=$ Value of added sample concentration; $\mathrm{AI}=$ Antioxidant activity index

Preparation of standard curves for the absorbance of DPPH against BHT concentration

BHT was dissolved once in methanol and another in isooctane to make $(0,0.5,1.0,2.0$ and $3.0 \mathrm{mM})$ and 5 $\mathrm{mL} 0.1 \mathrm{mM}$ DPPH in methanol (for biodiesel tests) or in isooctane (for oil tests) were added. The absorbance of DPPH was determined for 30 min for methanol and $96 \mathrm{~h}$ for oil.

\section{RESULTS AND DISCUSSION}

DPPH method for oil without antioxidant addition

Absorbance of DPPH from olive oil, Jatropha oil and used fried oil without antioxidant addition through thermal oxidation is shown in Fig. 2. Absorbance of DPPH in $2 \mathrm{~g}$ oils (olive, jatropha, used fried oil) were $0.142,0.267$ and 0.163 , respectively. The absorbance value of DPPH in isooctane without oils and without

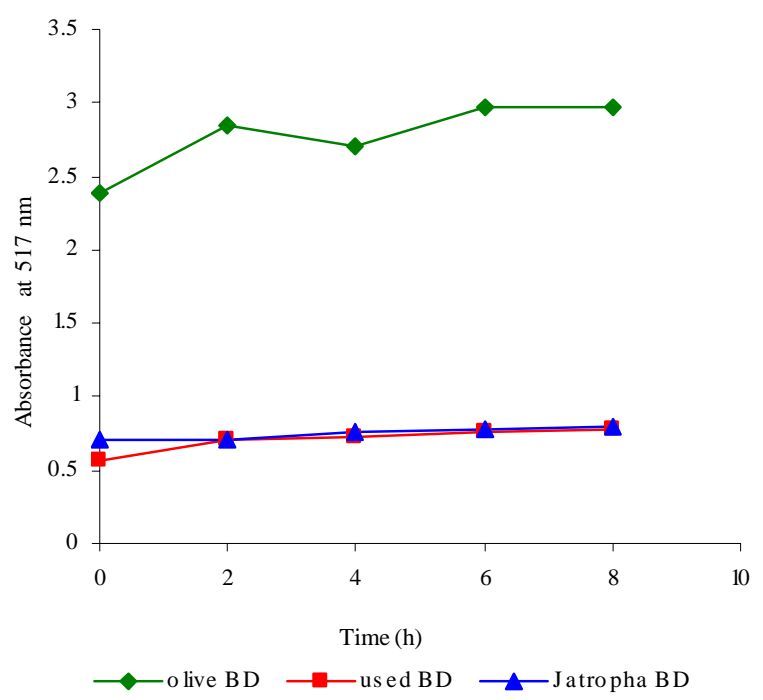

Fig. 3: Thermal degradation of biodiesel at $60{ }^{\circ} \mathrm{C}$ for tested oils 
addition of antioxidants was 1.326 . This indicated that oils itself have some compounds affecting the stability of DPPH. Changes of DPPH absorbance for thermally oxidized oils without antioxidant addition for $8 \mathrm{~h}$ are shown in Fig. 2. The absorbance chromatogram of DPPH for $2 \mathrm{~h}$ thermally oxidized olive oil showed slight increase compared to sample at $0 \mathrm{~h}$. Thus, the absorbance changes of DPPH from olive oil sample were indication for free radicals generated from oxidized oil. Irrespective of Jatropha oil and used fried oil, both samples showed a chromatogram of steady state up to $4 \mathrm{~h}$ - thermally oxidation and a gradual increase in absorbance appeared. This is due to less generated free radicals reacting with DPPH and increase absorbance of DPPH.

DPPH method for biodiesel without antioxidant addition

Absorbance of DPPH from olive biodiesel, Jatropha biodiesel and used fried oil biodiesel without antioxidant addition through thermal oxidation is shown in Fig. 3. Absorbance of DPPH for $2 \mathrm{~g}$ biobiesel (olive, Jatropha and use fried oil) were 2.38, 0.715 and 0.766, respectively. The absorbance value of DPPH in methanol without biodiesel and without addition of antioxidants was 2.305. This indicates that Jatropha biodiesel and used fried oil biodiesel have some compounds more than olive oil biodiesel affecting the stability of DPPH. Changes in DPPH absorbance through thermally oxidized biodiesel without

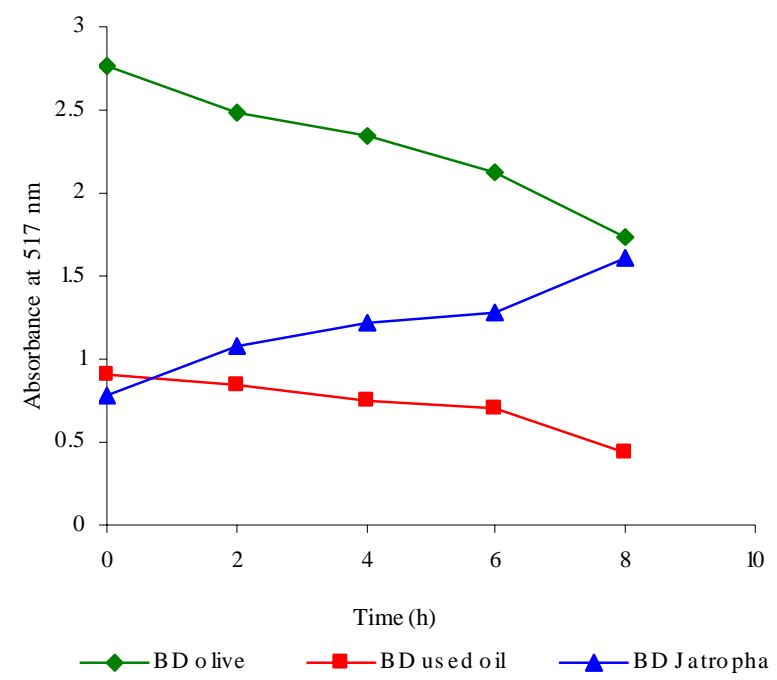

Fig. 4: Effect of BHT addition on thermal degradation of oils at $180{ }^{\circ} \mathrm{C}$ antioxidant addition for $8 \mathrm{~h}$ are shown in Fig. 3. The absorbance of DPPH at 2h-thermaly oxidized olive biodiesel showed slight increase than that sample at 0 h. The absorbance changes of DPPH of olive biobiesel samples were due to absence of free radicals generated from oxidized olive biodiesel indicating stability. Usedoil biodiesel samples showed slight increase in absorbance indicating less stability. Irrespective of Jatropha biodiesel showed a slight decrease up to 8hthermally oxidation and slight gradual increase in absorbance appeared. This is due to the decrease in generated free radicals reacted with DPPH and decrease absorbance of FPPH.

\section{DPPH method for oils with BHT addition}

The presence of BHT $0.25 \%$ concentration in olive oil decreased the absorbance of DPPH significantly. This oil containing free radical scavenging compounds such as BHT can decrease the absorbance of DPPH.

Changes of DPPH absorbance from thermally oxidized olive oil with BHT for $8 \mathrm{~h}$ are shown in Fig. 4. The absorbance of DPPH from 0 to $6 \mathrm{~h}$ remained nearly constant. However, as oxidation time increased beyond $6 \mathrm{~h}$, the increase of DPPH absorbance started and showed significant drop beyond $8 \mathrm{~h}$ oxidation. This is due to generated free radicals reacted with DPPH and decreased the absorbance of DPPH again. On the other hand, the Jatropha oil and used fried oil with BHT addition showed slight gradual increase in absorbance of DPPH as oxidation time increased showing a slight

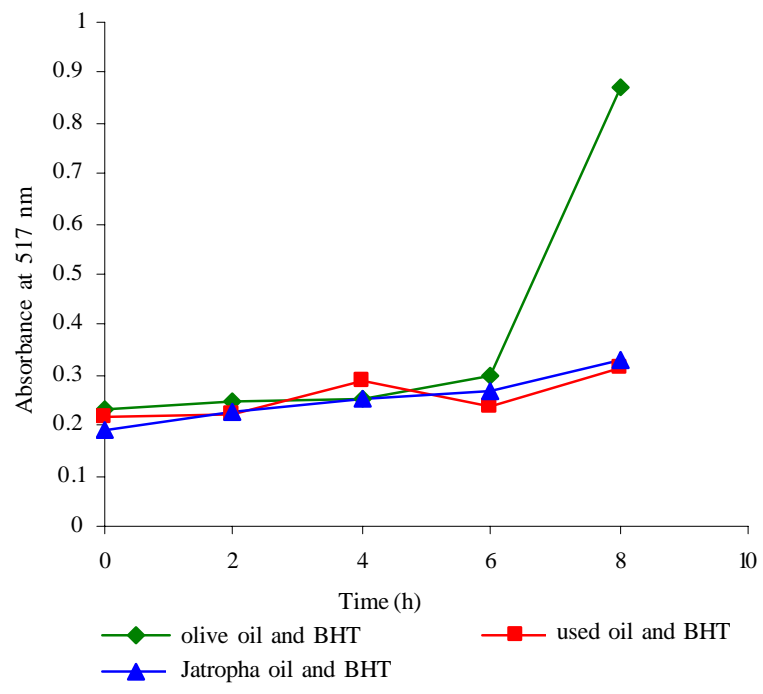

Fig. 5: Effect of BHT addition on thermal degradation of different biodiesels at $60{ }^{\circ} \mathrm{C}$ 
drop in absorbance after $6 \mathrm{~h}$ oxidation and increase in DPPH absorbance during $8 \mathrm{~h}$ oxidation.

Depend upon BHT addition to oil, the oxidation period needed for pattern changes were different Fig. 4. Oils with more free radical scavenging compounds need relatively long oxidation time to change.

\section{DPPH method for biodiesel with BHT addition}

Changes of DPPH absorbance for olive biodiesel, Jatropha biodiesel and used-oil biodiesel with BHT addition for studying thermal oxidation patterns is shown in Fig. 5. The absorbance of DPPH from $0 \mathrm{~h} \mathrm{-}$ $8 \mathrm{~h}$ for thermally oxidized olive biodiesel showed gradual decrease due to the generation of free radicals indicating reaction with DPPH. The absorbance of $\mathrm{DPPH}$ from $0 \mathrm{~h}-8 \mathrm{~h}$ thermally oxidized used-oil bodiesel showed the same pattern of olive biodiesel. Irrespectively, Jatropha biodiesel absorbance of DPPH showed an increase from $0 \mathrm{~h}-4 \mathrm{~h}$ thermally oxidiation and a slight decrease of DPPH absorbance with a steady state till $8 \mathrm{~h}$. This explains the changes in free radical generated from oxidation of Jatropha biodiesel. As oxidation time increased beyond $4 \mathrm{~h}$, the increase in DPPH absorbance indicating less free radical scavenging compounds. A reverse pattern for Jatropha biodiesel was shown for $4 \mathrm{~h}-8 \mathrm{~h}$ indicating decreasing DPPH absorbance which was taken for predicting the oxidative stability of biodiesel.

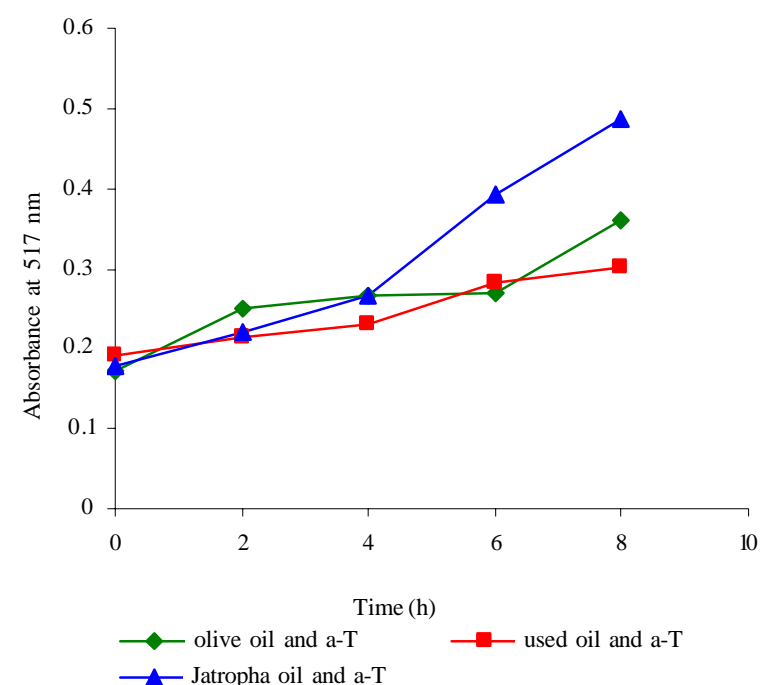

Fig. 6: Effect of a-t addition on thermal degradation of oils at $180{ }^{\circ} \mathrm{C}$
DPPH method for oils with $\alpha$-Tocopherol addition

The oxidation time for pattern changes is influenced by both initial concentration of lipid and free radicals. Olive oil, Jatropha oil and used fried oil with $0.25 \%$ $\alpha$-T addition and oxidation pattern changes shown in Fig. 6.

Olive oil oxidation pattern showed slight change after $6 \mathrm{~h}$ thermal oxidation due to the high inherent antioxidants. Fried oil needed $4 \mathrm{~h}$ oxidation time for the pattern change of DPPH absorbance. Jatropha oil showed highest free radical formation rate beginning from $0 \mathrm{~h}$ and giving the lowest oxidative stability with $0.25 \alpha$-Tocopherol addition.

\section{DPPH method for biodiesel with $\alpha$-Tocopherol addition}

Olive biodiesel, Jatropha biodiesel and used-oil biodiesel thermal oxidation patterns with $\alpha$ Tocopherol addition and absorbance changes with DPPH is shown in Fig. 7. Although the three biodiesel samples showed high stability with DPPH absorbance, but Jatropha oil-biodiesel showed slight increase in DPPH absorbance after $2 \mathrm{~h}$ and continued steady state pattern till $8 \mathrm{~h}$ oxidation. This phenomenon indicated that Jatropha biodiesel consumed $\alpha$-Tocopherol in $2 \mathrm{~h}$ oxidation time confirming less oxidative stability.

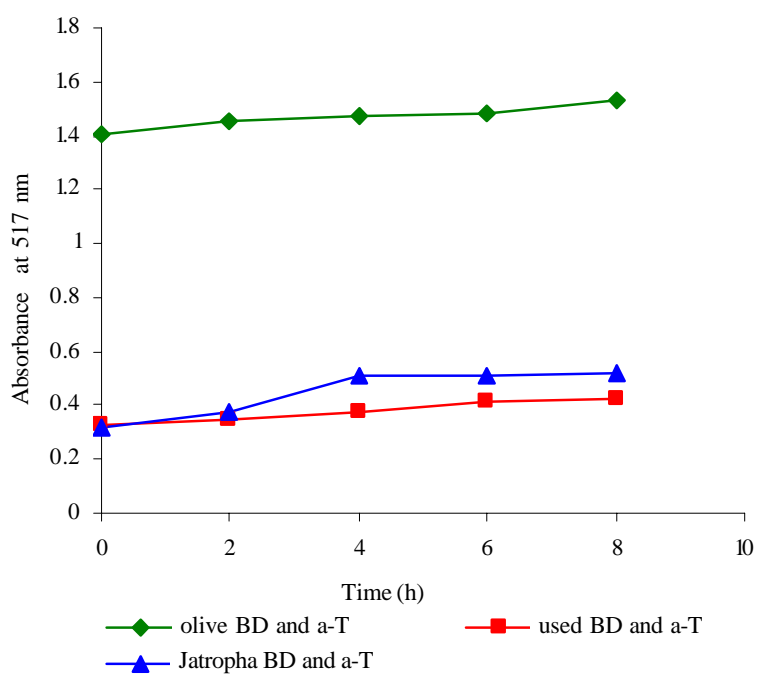

Fig. 7: Effect of a-t addition on the thermal degradation of biodiesel at $60{ }^{\circ} \mathrm{C}$ 
DPPH method for oils with Jatropha residue of root extract addition

The natural antioxidant activity of Jatropha residue root extract of concentration $0.25 \%$ was carried out to determine the effect of its addition to oils and their corresponding biodiesel with DPPH pattern changes is shown in Fig. 8.

Changes of DPPH absorbance for thermally oxidized olive oil with root extract residue slightly increased DPPH absorbance from $0 \mathrm{~h}$ to $2 \mathrm{~h}$ thermal oxidation and steady state pattern was shown till $4 \mathrm{~h}$ thermal oxidation and a continuous increase in DPPH absorbance was shown at $6 \mathrm{~h}$ and $8 \mathrm{~h}$ thermal oxidation Fig. 8.

DPPH method for biodiesel with Jatropha residue of root extract addition

The effect of natural antioxidant activity of root residue addition to biodiesel on changes of DPPH absorbance pattern of thermally oxidation is shown in Fig. 9.

The olive biodiesel showed change in DPPH absorbance pattern from $0 \mathrm{~h}$ to $2 \mathrm{~h}$ and a steady state in absorbance was shown on further thermal oxidation at $2 \mathrm{~h}$ to $6 \mathrm{~h}$. First increase was due to the release of free radical from root residue and reaction with DPPH. The steady state indicated the consumption of free radical to the biodiesel. On further thermal oxidation, the pattern showed increase in DPPH absorbance i.e. free

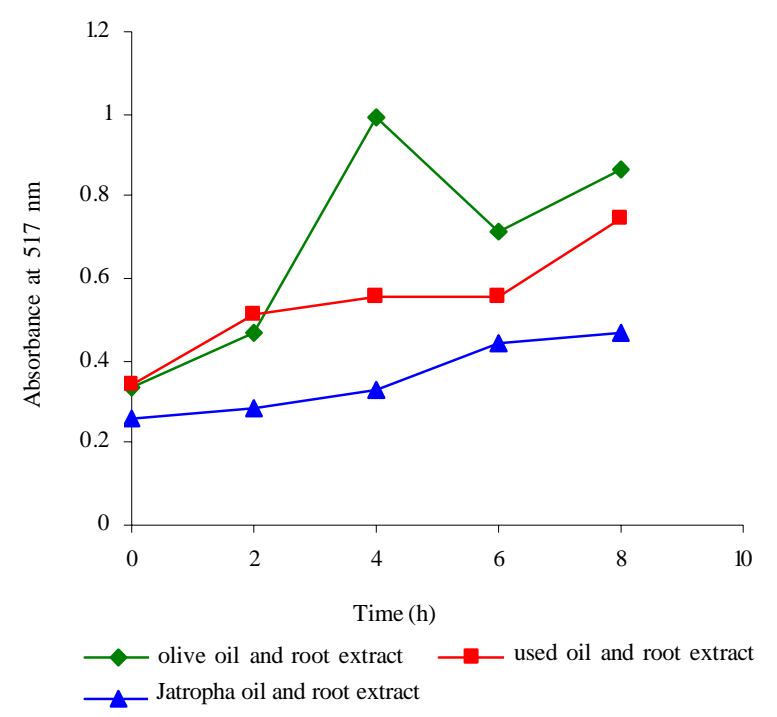

Fig. 8: Effect of root extract addition on thermal degradation of oil at $180{ }^{\circ} \mathrm{C}$ radical existed with no reaction with DPPH. Both usedoil biodiesel and jatropha biodiesel propagated the same pattern showing steady state from $0 \mathrm{~h}$ to $8 \mathrm{~h}$ thermal oxidation. This pattern indicated consumption of the antioxidant of Jatropha root residue addition. Thus, biodiesel needs more dose of residue root extract to achieve oxidative stability goal. The changes in DPPH pattern with addition of natural antioxidants confirm the protective effects which is attributed to high levels of phenolic compounds and collected results agreed with Ling et al. (2006).

DPPH method for addition of Jatropha residue of root extract with different concentrations

Jatropha oil and Jatropha biodiesel were tested for their antioxidant activity during thermally oxidizing at $180^{\circ} \mathrm{C}$ and $60^{\circ} \mathrm{C}$ for $8 \mathrm{~h}$, respectively. The addition of Jatropha residue root extract at different concentrations of 100, 220 and $400 \mathrm{mg} / \mathrm{L}$ were evaluated to act as antioxidant at optimum concentration needed for oil and /or biodiesel as shown in Figs. 10 and 11. 3.9.1 DPPH method for addition of Jatropha residue root extract with fresh Jatropha oil:

Absorbance of DPPH in isooctane with addition of (100,220 and $400 \mathrm{mg} / \mathrm{L}$ ) residue root extract to Jatropha oil is shown in Fig. 10. Changes of DPPH absorbance from thermally oxidized Jatropha oil with addition of $100 \mathrm{mg} / \mathrm{L}$ residue (Jatropha root extract) at $0 \mathrm{~h}$ to $1.5 \mathrm{~h}$

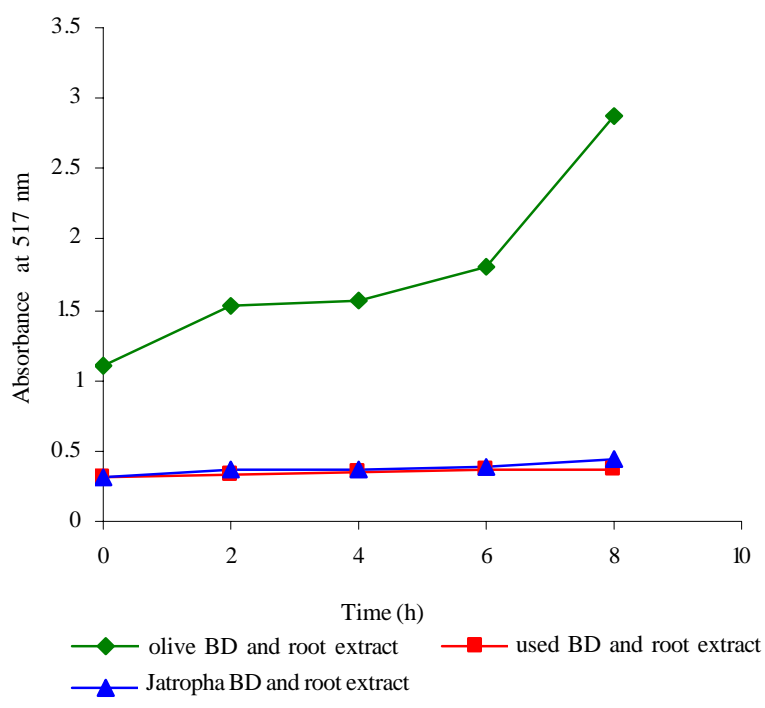

Fig. 9: Effect of root extract addition on the thermal degradation of biodiesel at $60{ }^{\circ} \mathrm{C}$ 
significantly decreased during oxidation due to the free radicals generated from oxidized Jatropha oil and reacted with DPPH. As oxidation time increased beyond $1.5 \mathrm{~h}$, the DPPH absorbance in Jatropha oil pattern started to increase depending on the concentration of residue of root extract in oil. Jatropha oil with $220 \mathrm{mg} /$ $\mathrm{L}$ residue of root extract showed a reverse pattern, as oxidation time increase at $0 \mathrm{~h}$ to $6 \mathrm{~h}$ a gradual increase

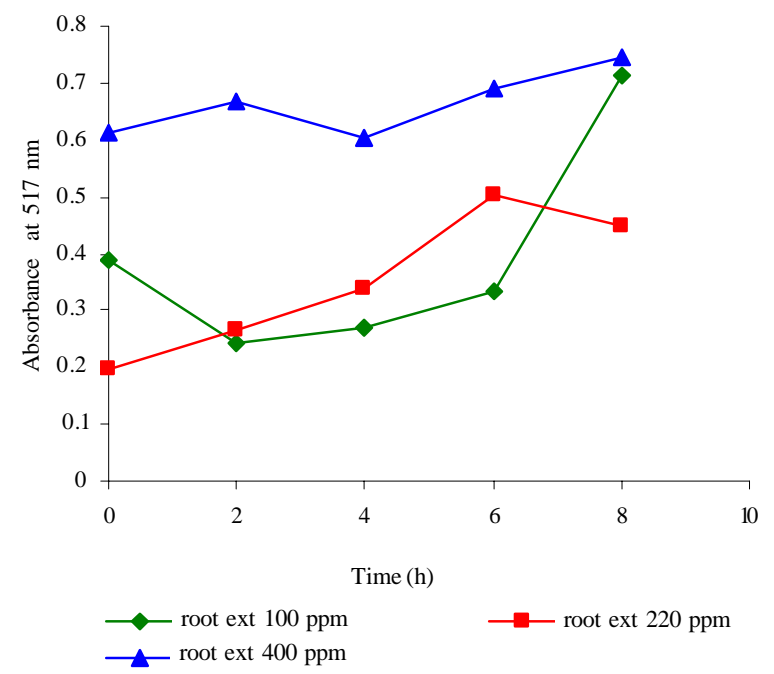

Fig. 10: Effect of Jatropha root extract addition to fresh Jatropha oil on oxidation stability

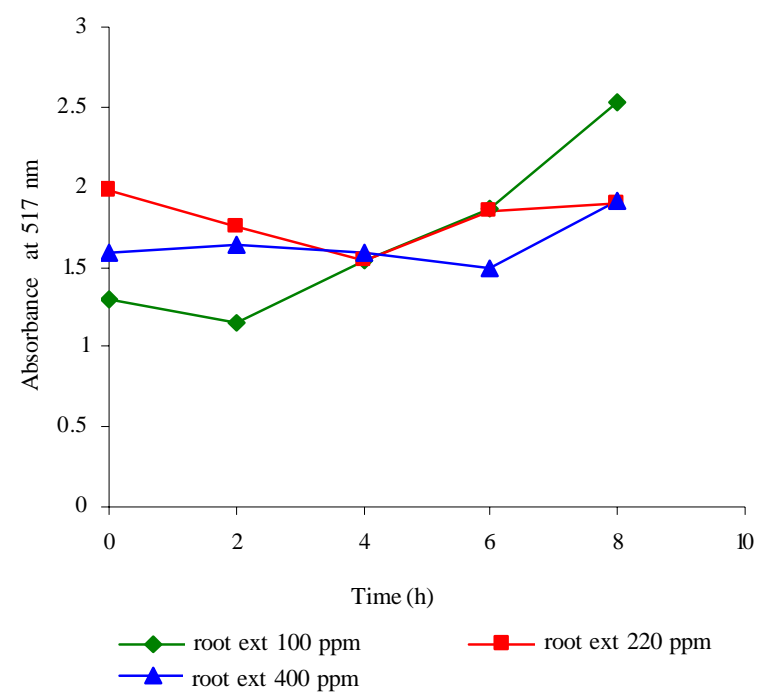

Fig. 11: Effect of root extract addition to Jatropha biodiesel on oxidative stability in DPPH absorbance is shown. On further increase in oxidation time beyond $0 \mathrm{~h}$ to $8 \mathrm{~h}$, a decrease in $\mathrm{DPPH}$ absorbance in Jatropha oil is evaluated indicating lack in antioxidants. The absorbance of DPPH in Jatropha oil with $400 \mathrm{mg} / \mathrm{L}$ residue of root extract addition significantly showed a steady state pattern indicating equivalent antioxidant dose to be used in Jatropha oil for oxidative stability needed. Results agreed with Lee et al. (2007) who stated that DPPH method is valid for the prediction of oxidative stability of fresh oil because highly oxidized oils can not be differentiated.

DPPH method for addition of Jatropha residue (root extract) with corresponding biodiesel

Absorbance of DPPH in methanol with addition of residue of (Jatropha root extract) in different concentrations (100, 220 and $400 \mathrm{mg} / \mathrm{L}$ ) to Jatropha biodiesel is shown in Fig. 11. For thermally oxidized Jatropha oil-biodiesel with addition of $100 \mathrm{mg} / \mathrm{L}$ residue (Jatropha root extract) at $0 \mathrm{~h}$ to $2 \mathrm{~h}$ a decrease in DPPH absorbance indicating biodiesel with little radical scavenging compounds. As oxidation time increased from $2 \mathrm{~h}$ to $8 \mathrm{~h}$, a gradual increase in DPPH absorbance is shown indicating lack of oxidative stability. Changes of DPPH absorbance due to thermally oxidized Jatropha biodiesel with addition of $220 \mathrm{mg} / \mathrm{L}$ residue (Jatropha root extract) at $0 \mathrm{~h}$ to $6 \mathrm{~h}$ were insignificant showing a steady state pattern indicating stability of Jatropha oil-biodiesel. As oxidation time increased at $6 \mathrm{~h}$ to $8 \mathrm{~h}$ an increase in DPPH absorbance is shown indicating a reverse pattern. A steady state pattern is shown at $0 \mathrm{~h}$ to $8 \mathrm{~h}$ thermally oxidized Jatropha biodiesel with 400 $\mathrm{mg} / \mathrm{L}$ addition of residue (Jatropha root extract). The pattern indicated the equivalent antioxidant dose to be used in Jatropha biodiesel for oxidative stability needed.

\section{CONCLUSION}

- Pattern changes of DPPH absorbance from a positive to negative slope indicates the concentration of hydrogen donating antioxidant compounds in oil / or biodiesel before thermal oxidation.

- The increase rate of DPPH absorbance is related to the amount of alkoxyl (RO) ,peroxyl (RO) and alkyl radical( $\mathrm{R}$ ) generated from oxidized lipids.

- The oxidation time for pattern change indicates the period for complete consumption of inherent hydrogen donating antioxidant compounds by lipid free radicals. 
- Addition of synthetic antioxidants as (BHT) $0.25 \%$ to (Olive, used fried and Jatropha) oils showed good oxidation stability up to $6 \mathrm{~h}$. Although $(\alpha-\mathrm{T})$ addition of $0.25 \%$ to tested oil but Jatropha oil showed less oxidative stability after $2 \mathrm{~h}$ thermal oxidation and olive oil showed more oxidative stability up to $6 \mathrm{~h}$ thermally oxidation. Irrespectively addition of residue (Jatropha root extract) in $0.25 \%$ to oils showed poor pattern to thermal stability due to the use of crude extract.

- Addition of natural antioxidant compounds from natural sources tested with DPPH method succeeded to detect the optimum dose needed for oxidative stability for oils and thier corresponding biodiesel.

- Addition of synthetic antioxidant (BHT) at $0.25 \%$ to biodiesel (olive, used fried and Jatropha) showed changing pattern indicating poor oxidative stability. A reverse pattern was shown on $(\alpha-\mathrm{T})$ at $0.25 \%$ addition with biobiesel indicating good oxidative stability upon thermally oxidation. The residue (Jatropha root extract $0.25 \%$ ) addition with biodiesel was effective with Jatropha biodiesel and used fried biodiesel. Irrespective to olive biodiesel which showed reverse pattern.

- Testing $100 \mathrm{mg} / \mathrm{L}, 220 \mathrm{mg} / \mathrm{L}$ and $400 \mathrm{mg} / \mathrm{L}$ residue (Jatropha root extract) with fresh Jatropha oil and /or biodiesel indicated the optimum oxidation stability needed from natural extract to be $400 \mathrm{mg} / \mathrm{L}$. Obtained results show that residue addition of (Jatropha root extract) can be used as antioxidant to improve the oxidation stability of vegetable oils and biodiesel.

\section{ACKNOWLEDGEMENTS}

The authors wished to thank National Research Center, Chemical Engineering Department for their complementary of Jatropha plant and seeds. Thanks are also given to staff of processing group for their technical assistance.

\section{REFERENCES}

Ali, Y.; Hanna, M. A.; Leticus, L. I., (1995). Emissions and power characteristicsof diesel engines on methyl soyate and diesel fuel blends. Bioresou. Tech., 52 (2) 185-195 (11 pages).

Bej, S. K., (2002). Performance evaluation of hydro processing catalyst - a review of experimental techniques. Energ. Fuel, 16 (3), 774-784 (11 pages).

Bouaid, A.; Martinez, M.; Aracil, J., (2007). Long storage stability of biodiesel from vegetable and used frying oils. J. Fuel, 86 (16), 2596-2602 (7 pages).

Dunn, R. O., (2001). Alternative jet fuels from vegetable oils. T. ASAE, 44 (6), 1751-1757 (7 pages).
Dunn, R. O.; Knoth, G., (2003). Oxidative stability of biodiesel in blends with jet fuel by analysis of oil stability index. J. Am. Oil Chem. Soc., 80 (10), 1047-1048 (2 pages).

Gertz, C.; Klosternmann, S., Kochhar, S. P., (2000). Testing and comparing oxidative stability of vegetable oils and fats at frying temperature. Eur. J. Lipid Sci. Tech., 102 (8-9), 543-551 (9 pages).

Gertz, C.; Kochhar, S. P., (2001). A new method to determine oxidative stability of vegetable fats and oils at simulated frying temperature. OCL-Ol Corps Gras Li., 8 (1), 82-88 (7 pages).

Gubitz, G. M.; Mittlebeach, M.; Trabi, M., (1999). Exploitation of tropical oil seed plant Jatropha curcas L. Biosource Tech., 67 (1), 73-82 (10 pages).

Hawash, S.; Kamal, N.; Zaher, F.; Kenawi, O.; El Diwani, G., (2009). Biodiesel fuel from Jatropha oil via non-catalytic supercritical methanol transesterification. Fuel, 88 (3), 579582 (4 pages).

Hui, Y. H., (1996). Bailey's industrial oil and fat products $5^{\text {th. }}$ Ed., 4, 411.

Jeong, S. M.; Kim, S. Y.; Kim. D. R.; Jo, S. C.; Nam, K. C.; Ahn, D. U.; Lee, S. C., (2004). Effect of heat treatment on the antioxidant activity of extracts from citrus peels. J. Agr. Food Chem., 52 (11), 3389-3393 (5 pages).

Kaushik, N.; Kumar, K.; Kumar, S.; Kaushik, N.; Roy, S., (2007). Genetic variability and divergence studies in seed traits and oil content of Jatropha (Jatropha curcas L.) accessions. Biomass Bioenerg., 31 (7), 497-502 (6 pages).

Knothe, G., (2007). Some aspects of biodiesel oxidative stability. Fuel Process. Tech. 88 (7), 669-677 (9 pages).

Kumara, R.; Sharma, M.; Sinharay, S.; Sarin, R., (2004). Effect of alkyl chain on biodiesel characteristics, SAF Publication No 2004-28-027.

Lee, J.; Chung, H.; Chaug, P. S.; Lee, J. H., (2007). Development of a method predicting the oxidation stability of edible oils using 2,2-diphenyl -1-picrylhydrazl (DPPH). Food Chem., 103 (2), 662-669 (8 pages).

Ling, Y. C.; May, C. Y.; Foon, C. S.; Ngan, M. A.; Hock, C. C.; Basiron,Y., (2006). The effect of natural and synthetic antioxidants on the oxidation stability of palm diesel. Fuel, 85 (5-6), 867-870 (4 pages).

Lui, Q.; Yao, H., (2007). Antixidant activities of barly seeds extracts. Food Chem., 102 (3) $732-737$ (6 pages).

Makkar, H. P. S.; Beaker, K.; Sporer, F.; Wink, M., (1997). Studies on nutritive potential and toxic constituents of different provenances of Jatropha curcas. J. Agr. Food Chem., 45 (8), 3152-3157 (6 pages).

Mc Cormick, R. L.; Ratcliff, M.; Moens, L.; Lawrence, R. (2007). Several factors affecting the stabilityof biodiesel in standard accelerated tests. Fuel process. Tech., 88 (7), 651(7 pages).

Mc Cormick, R. L.; Terry, B.; Natarajan, M., (2006). Impact of biodiesel blends on fuel system components durability, SAE Techn. Doc. No. 2006-01-3279.

Salimon, J.; Abdullah, R., (2008). Physiocochemical properties of Malaysian Jatropha curcas seed oil. Sains Maysiana, 37 (4), 379-382 (4 pages).

Sarin, R.; Sharma, M.; Sinharay, S.; Malhtra, R. K., (2006). Jatropha - Palm biodiesel blends an optimum mix for Asia. Fuel, 86 (10-11) 1365-1371 (7 pages). 
Shahidi, E., (1997). Natural antioxidants: An overview, In: Natural Antioxidants, Chemistry, Health Effects and Applications, Ed. F. Shahidi, AOCS Press Champaign, Illinois, USA, 1-10.

Shay, E. G., (1993). Diesel fuel from vegetable oils: Status and opportunities. Biomass Bioenerg., 4 (4), 227-242 (16 pages).

Srivastava, A.; Prasad, R., (2000). Triglycerides-based diesel fuels. Renew. Sust. Energ. Rev., 4 (2) 111-133 (23 pages).

Tarandjiska, R. B.; Marekov, I. N.; Niklilova-Damyanova, B. M.; Amidzhin, B. S., (1996). Determination of triacylglycerol classes and molecular species in seed oils with high content of linoleic and linolenic acids. J. Sci. Food Agr., 72 (4), 403-410 (8 pages).

Van Gepen, J. H.; Hammond, E. G.; Yu, L., Monyem, A. (1997).
Determining the influence of contaminants on biodiesel properties, SAE Techn. Doc. No. 971685.

Waynick, J. A., (2005). Characterization of biodiesel oxidation and oxidation products: CRC Project No. AVFL - 2b. National Renewable Energy Laboratory, NREL/TP -540- 39096.

Westbrook, S. R., (2005). An evaluation and comparison of test methods to measure the oxidative stability of net biodiesel. Subcontract report. National Renewable Energy Laboratory, NREL/SR-540-38983.

Wijtmans, M.; Pratt, D. A.; Brinkhorst, J.; Serwa R., Volgimigli L.; Pedulli, G. F.; Porter, N. A., (2004). Synthesis and reactivity of some 6-substituted-2,4-dimethyl 1-3-pyridinols, a novel class of chain breaking antioxidants. J. Org. Chem., 69 (26), 9215-9223 (9 pages).

\section{AUTHOR (S) BIOSKETCHES}

El Diwani, G., Ph.D., Professor of chemical engineering, National Research Center, Department of Chemical Engineering, Egypt.

Email: geldiwani@yahoo.com

El Rafie, S., Ph.D., Assistant professor of Chemistry, National Research Center, Department of Chemical Engineering, Egypt.

Email: shelrafie0000@yahoo.com

Hawash, S., Ph.D., Professor of chemical engineering, National Research Center, Department of Chemical Engineering, Egypt.

Email:dr_shawash@yahoo.com 